\title{
Research
}

\section{Barriers and facilitators to integration of physician associates into the general practice workforce:}

\author{
a grounded theory approach
}

\begin{abstract}
Background

Physician associates (PAs) are described as one solution to workforce capacity in primary care in the UK. Despite new investment in the role, how effective this will be in addressing unmet
\end{abstract} primary care needs is unclear.

\section{Aim}

To investigate the barriers and facilitators to the integration of PAs into the general practice workforce.

\section{Design and setting}

A modified grounded theory study in a region unfamiliar with the PA role.

\section{Method}

No a priori themes were assumed. Themes generated from stakeholder interviews informed a literature review and theoretical framework, and were then tested in focus groups with GPs, advanced nurse practitioners (ANPs), and patients. Recorded data were transcribed verbatim, and organised using NVivo version 10.2.2, with iterative analysis of emergent themes. A reflexive diary and independent verification of coding and analysis were included.

\section{Results}

There were 51 participants (30 GPs, 11 ANPs, and 10 patients) in eight focus groups. GPs, ANPs, and patients recognised that support for general practice was needed to improve access. GPs expressed concerns regarding PAs around managing medical complexity and supervision burden, non-prescriber status, and medicolegal implications in routine practice. Patients were less concerned about specific competencies as long as there was effective supervision, and were accepting of a PA role. ANPs highlighted their own negative experiences entering advanced clinical practice, and the need for support to counteract stereotypical and prejudicial attitudes

\section{Conclusion}

This study highlights the complex factors that may impede the introduction of PAs into UK primary care. A conceptual model is proposed to help regulators and educationalists support this integration, which has relevance to other proposed new roles in primary care.

\section{Keywords}

acceptability of health care; general practice; healthcare delivery; interprofessional relations physician assistant.

\section{INTRODUCTION}

The NHS is under unprecedented pressure, and problems with workforce capacity are leading to difficulties in people accessing help when they need it.1-3 The physician associate (PA) has been suggested as one professional role that might support primary care but it is unclear how effective this will be. ${ }^{4}$

The role of the PA was originally developed in the US in the 1960s, primarily as a method of increasing access to health care for underserved communities. ${ }^{5}$ In 2003, a number of PAs were recruited from the US to both accident and emergency (A\&E) and general practice in the West Midlands in response to an acute workforce shortage at the time. ${ }^{6}$ The first UK-trained PAs graduated in 2009 and, as the ongoing workforce crises in A\&E and primary care continue, new interest in the role has surfaced, with Health Education England now starting to invest in its development. ${ }^{2,4}$

A review into the role of PAs in general practice showed a mixed response from the profession, despite emerging evidence of the acceptability, effectiveness, and utility from organisations that already employ them. ${ }^{\text {? }}$

The University of Sheffield commenced its own Diploma in Physician Associate Studies in 2016, with a focus on contributing to the community workforce in an area unfamiliar with the role. In designing the delivery of a curriculum to support this, the research question emerged: 'What are the barriers

B Jackson, MMedEd, MRCP, MRCGP, senior clinical teacher, Academic Unit of Primary Medical Care; M Marshall, MEd, PhD, director of learning and teaching. Academic Unit of Medical Education, University of Sheffield, Sheffield. S Schofield, MSc $\mathrm{PhD}, \mathrm{PGCE}$, senior lecturer, Centre for Medical Education, University of Dundee, Dundee.

\section{Address for correspondence}

Ben Jackson, Academic Unit of Primary Medical Care, University of Sheffield, Western Bank and facilitators to the integration of physician associates into the general practice workforce?' To investigate this, a modified grounded theory study was undertaken.

\section{METHOD}

\section{Study design}

A modified grounded theory approach was used with no a priori themes assumed. ${ }^{8}$ Instead, themes generated from interviews with stakeholders were used to derive a theoretical framework and define search terms for a focused scoping review of the literature. This framework was then tested in stakeholder focus groups to create a conceptual model describing key barriers and facilitators to the integration of the PA role into general practice teams within the region. A reflexive diary was discussed regularly with one of the authors, who had no prior experience of the field.

\section{Data collection}

Initial fieldwork. During 2015, fieldwork data were collected lusing notes and transcribed audiotaped recordings) from discussions with stakeholders including clinical commissioning groups (CCGs), Health Education England, GPs, and established PA educators on the potential for integration of PAs into the primary care workforce.

Scoping review of the literature. A scoping review ${ }^{9}$ of the international literature in Medline and Cinahl databases using the

Sheffield, S10 2TN, UK

E-mail: ben.jacksondasheffield.ac.uk Submitted: 17 April 2017; Editor's response: 23 May 2017; final acceptance: 3 July 2017. CBritish Journal of General Practice This is the full-length article (published online 10 Nov 2017) of an abridged version published in print. Cite this version as: Br J Gen Pract 2017; DOI: https://doi.org/10.3399/bjgp17X693113 


\section{How this fits in}

Physician associates are increasingly described as part of the solution to workforce shortages in general practice, with little evidence on how easily this might be achieved. This qualitative study builds a useful model for regulators and educationalists on the significant facilitators /medical training, continuity of care, workforce shortage, and patient acceptability) and barriers (managing uncertainty and complex presentations, indemnity arrangements, and professional boundaries) to their successful integration into primary care teams. Other factors (prescribing, supervision arrangements) were not found to be as significant barriers.

following MESH headings was undertaken: [physician associate or physician assistant] - and - [primary care, general practice, primary health care or primary medical care]. This search was then refined using MESH terms derived directly from themes generated from the initial fieldwork. Abstracts of those papers available in English were reviewed, with full-text reviews for those with clear relevance to the subject matter (Table 1).

Focus groups. The emerging themes were developed into an interview topic guide for further exploration in focus group discussion with patients, GPs, and advanced clinical practitioners in the region, facilitated by a trained researcher. The topic guide for these focus groups covered the following areas: workforce and access, safety and supervision, approach to care, politics and the future of NHS services, and professional identity. Demographic data on focus group participants are provided in Table 2.

Table 1. MESH terms derived from fieldwork used to refine literature, and numbers of papers reviewed and retained

\begin{tabular}{llcc} 
Overarching theme & MESH term & Reviewed & Retained \\
\hline Integration & Attitude of health personnel & 78 & 19 \\
& Interprofessional relations & 47 & 11 \\
& Patient care team & 64 & 20 \\
\hline Service delivery & Health staffing & 42 & 28 \\
& Delivery of health care & 68 & 10 \\
& Medically underserved area & 50 & 17 \\
\hline Quality & Quality of health care & 65 & 11 \\
& Patient satisfaction & 23 & 11 \\
& Continuity of health care & 11 & 4 \\
\hline
\end{tabular}

\section{Data analysis}

All focus groups were audiotaped and transcribed verbatim with subsequent checking for accuracy where clarification was required. Focus groups continued until no new themes emerged, with focus group data analysed using thematic analysis. Thematic coding to identify individual concepts and themes using NVivo 10.2.2 was undertaken by the principal author, with analysis and relationships between concepts and themes revisited as new data emerged. An independent review of the coding and process of analysis was undertaken by another author.

\section{Sampling and recruitment}

Convenience maximum variety sampling was used to construct initial focus groups. GP groups were drawn from the postgraduate training community and patients from established links with the medical school for teaching purposes. Purposive sampling was then used to identify a younger group of GPs not involved with postgraduate education. Two groups with established advanced nurse practitioners (ANPs) in general practice were arranged, as the fieldwork data indicated their position would also be important to decisions regarding the employment of PAs. A total of eight focus groups were undertaken.

\section{RESULTS}

\section{Fieldwork}

Themes emerging from the fieldwork data were developed into a theoretical framework (Figure 1).

Key concerns from GPs focused on political motives to privatise the NHS or undermine general practice as a profession, whereas CCG leaders were more open to the PA role, although most were sceptical about whether the numbers would be sufficient to make a significant difference, and some had concerns about investing in them without any guarantee that they would remain in primary care. GPs also had concerns about how the new practitioners would fit into their teams, particularly without the ability to write prescriptions, and there was a recurring theme about whether PAs could operate safely when skills dealing with complexity and medical uncertainty were required, with related concerns about supervision requirements. As employers, GPs also had concerns about cost-effectiveness in comparison with other advanced clinical practitioners, and worries about PAs taking jobs from doctors in the future. Finally, there was an underlying concern from all stakeholders about whether patients would 


\section{Table 2. Demographics of focus group participants}

\begin{tabular}{lccc}
$\begin{array}{c}\text { GPs } \\
(\boldsymbol{n}=\mathbf{3 0})\end{array}$ & $\begin{array}{c}\text { ANPs } \\
(\boldsymbol{n}=\mathbf{1 0})\end{array}$ & $\begin{array}{c}\text { Patients } \\
(\boldsymbol{n}=\mathbf{1 1 )}\end{array}$ \\
\hline Male & 10 & - & 5 \\
\hline Female & $18(2)^{\mathrm{a}}$ & 10 & 6 \\
\hline $31-40$ years & 12 & 2 & 0 \\
\hline $\mathbf{4 1 - 5 0 \text { years }}$ & 8 & 1 & 2 \\
\hline $51-60$ years & 8 & 7 & 1 \\
\hline$\geq 61$ years & 2 & 0 & 8 \\
\hline Training practice & 23 & 5 & $\mathrm{~N} / \mathrm{A}$ \\
\hline Partner & 26 & 1 & $\mathrm{~N} / \mathrm{A}$ \\
\hline Salaried & 4 & $7(2)^{a}$ &
\end{tabular}

Figure 1. Theoretical framework for important themes regarding barriers and facilitators to integration of physician associates into the primary care workforce. $C C G$ = clinical commissioning group. accept these new professionals. These emerging themes were used to direct a subsequent scoping review of the literature, and to then create a topic guide to formally test in the focus groups.

\section{Focus groups} the demand and lack of workforce available to meet it was strongly confirmed by all the GP and ANP groups. The GP groups with concerns about this theme expressed them with a stronger emotional content than any other, using emotive language to reflect their concern about the sustainability of the situation. ANPs also recognised that the demand for care was extremely high, and that it was having an effect on access. Patients reflected the other side of the workforce-access equation, describing
Demand and access. The concern about

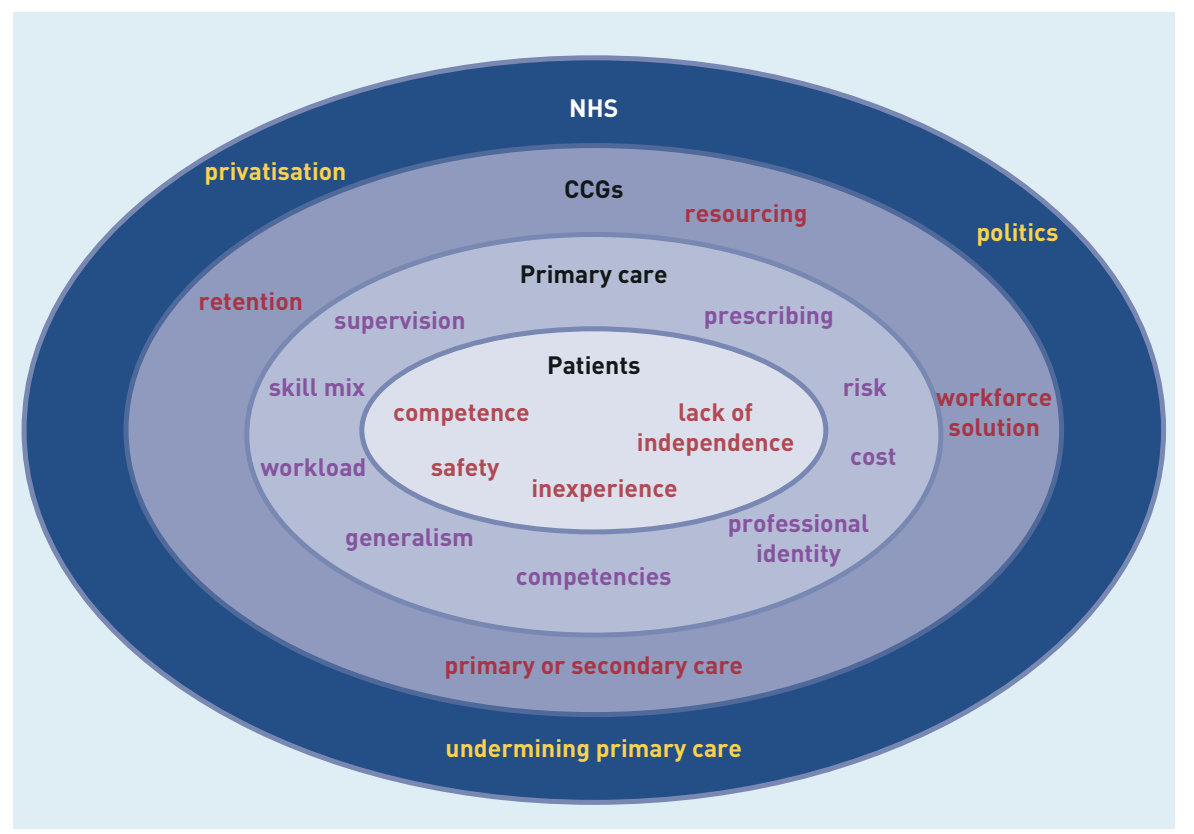

how difficult it was sometimes to get care, but showed sympathy for practitioners, explaining that they thought the system as a whole was at fault.

What we were talking about is the fact that we're bloody drowning in work and we can't actually do it.'(GP, Group 1)

We consider ourself fully staffed as a practice, but I could still see a role for this new generation of healthcare workers ... to ease pressure and make access for patients easier.' (ANP, Group 1)

'We've got more work than we'll ever be able to cope with, so any extra hands on board, great, and we'll find something for these guys to do, no problem.' (GP, Group 1)

It's not the fault of the GPs. They're doing everything they can to meet the demand. It's the system, somehow, that doesn't seem to work.' (Patient, Group 2)

Safety, supervision, and prescribing. Concerns about safety and supervision were mixed. Some GPs were clearly concerned about the lack of prescribing rights, which was repeatedly mentioned, and led to concern that the level of supervision required and additional responsibility was unattractive to them. Some, however, were much more positive, and patients expressed much less concern about practitioners requiring supervision levels, but were perplexed by the prescribing regulations.

I don't know how the physician associates have the experience to know what they don't know.' (GP, Group 3)

If you think ... like someone coming out of medical school, they're no bloody good, are they, to anybody, they've got to be trained after that.' (GP, Group 1)

You would end up having to actually re-evaluate them in all the areas before you could set them [work]. '(GP, Group 3)

'It's more the fact that we're still taking that responsibility, with someone else doing the assessment, and feels uncomfortable still.' (GP, Group 4)

I would feel reassured, generally, if the person was honest and using the advice that they could get and would begin to refer it up the line, and I think that's absolutely fine.' (Patient, Group 1) 


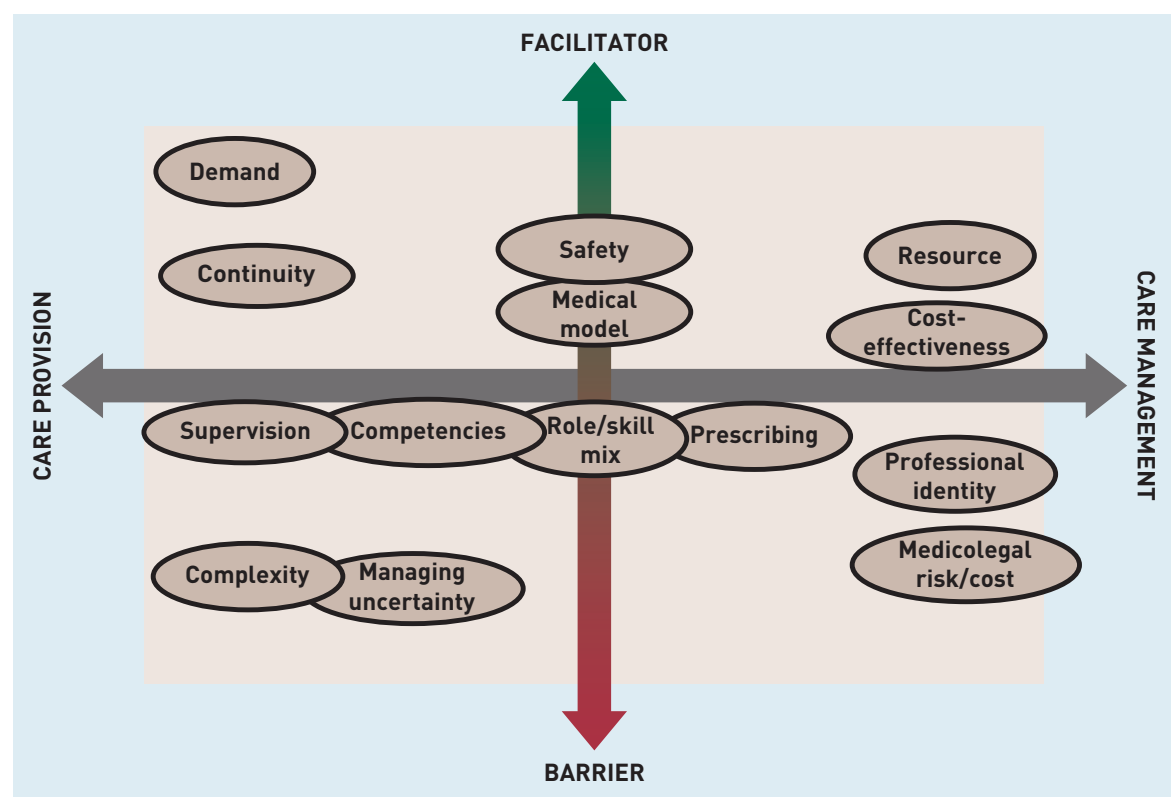

Figure 2. Conceptual model of the barriers and facilitators to integration of physician associates into general practice teams in a region unfamiliar with the role.
And whose responsibility does the prescribing come down to if they can't actually sign the script? It's down to you. (GP, Group 2)

'Yeah, if you've got the education and ability to be able to enact a treatment plan ... but you're then not ... qualified enough to prescribe.' (Patient, Group 1)

Generalist approach to health care. A general unfamiliarity with the role led to uncertainty about whether a PA would be able to operate in a general practice setting, and all felt that the context of their training was critical. Being trained in a traditional medical model emerged as a previously unidentified facilitator, and opinion was mixed about whether PAs would be able to practise holistically. Concerns were much stronger about their ability to help with managing complex presentations, uncertainty, and risk. Conversely, concerns from GPs in the fieldwork regarding continuity were not supported in the focus groups with patients, and ANPs agreed that it would support their experiences of continuity of care.

"I think lots of different "agencies" [sic] do think holistically now, and I don't think that is special to GPS.' (GP, Group 4)

Occasionally, I end up looking in notes and thinking: "Oh, that really needed to have seen a GP initially, because, actually, that's much more complicated. "' (GP, Group 4)

We have the skills ... to actually put a closure on something, and say: "Your headache is actually a tension headache." (GP, Group 1)

'Potentially, anything can be serious, but is a sort of a serious set of conditions, that's when you feel you need to see a GP, and I think there is a real distinction between the two.' (Patient, Group 1)

'Yeah, it does have the potential to provide more continuity, because they do talk about having mini-teams within practice, don't they?' (GP, Group 4)

Politics, professional boundaries, and skill mix. The concerns about the PA role being part of a political agenda to increase private provision in the NHS were not supported in the groups, although patients recognised how GPs could feel that their role was being undermined. There was an underlying general antipathy expressed towards the PA role by some GPs, with strong statements made by a small number. Such positions were recognised by the ANPs from when they had first taken on their new roles. Other GPs expressed a more ambivalent position, with a small minority much more positive. Overall, there was a significant lack of understanding of what the role of a PA was, and where and how they would fit into primary care teams.

The issue of undermining general practice was mentioned:

'The sceptics in us would say, yes, it is a deliberate attempt to undermine general practice.' (GP, Group 3)

And, there is that thing of devaluing general practice, but I think there is scope for diversity and I think, unfortunately, we do have to diversify.' (GP, Group 2)

It could be translated that way, if it's not presented to the public correctly. If they're presented as ... professionals assisting the doctors. They're not a cheap option. That is how it needs to be put over.' (Patient, Group 2)

On discussing privatisation, remarks were:

'No, I wouldn't ... I wouldn't see it like that. (GP, Group 2)

'But I don't think these roles have really got anything to do with that.' (ANP, Group 1)

GP attitudes to new roles were: 
But in those days, GPS were against first contact.' (ANP, Group 1, talking about an advanced practice role)

'I don't think it's a very valid role, somehow. [Laughing] Because it seems a kind of halfway thing. It's neither one thing, or the other.' (GP, Group 2)

'I don't see them as colleagues; I don't see them as partners; I see them as employees, and, I'm going to use a lovely politically incorrect word, as "subordinates", not associates.' (GP, Group 3)

'I don't feel threatened by it at all.' (GP. Group 1)

\section{Opinions on skill mix were:}

I actually think that this, in fact, could be a real advantage over the nurses.' (GP, Group 1 , talking about being trained in a generalist medical modell

My real query is, where does the physician assistant sit in amongst the way that our practice works at the moment?' (GP, Group 1)

" think I struggle with knowing where they are going to fit. Are they going to be an underpaid doctor or an overpaid nurse? (ANP, Group 2)

\section{Conceptual model}

Following independent verification of the analysis, discussion of the results led to the production of a final conceptual model, to summarise and illustrate the key facilitators and barriers identified to the integration of PAs into the general practice workforce (Figure 2).

\section{DISCUSSION}

\section{Summary}

Workforce requirements and problems accessing health care were confirmed as strong facilitators to the integration of PAs into the workforce. Participants' views were so strong in this area that it could be suggested that it promoted the more pragmatic views when themes such as skill mix and competencies were discussed as, despite a lack of knowledge of the role, some GPs gave the clear message: We have to make this work.' This pragmatic approach reflects opinion from parts of the world more familiar with PAs, where there is a recognition of the need for regional and national strategies regarding regulation to enable PAs to contribute fully. ${ }^{5,10}$ The possibility of increased continuity that the potential additional workforce presented was popular with patients, who explained that they valued relational continuity with all clinical practitioners in primary care. This was mirrored by the advanced nurse practitioners: provision of continuity of care became a facilitator rather than a barrier. Taken together, the number and strength of comments from GPs relating to the complexity of presentations in general practice, and the need to manage uncertainty (recognised as significant challenges by ANPs), confirmed this as one of the strongest barriers to a successful integration of new graduates into the workforce. Evidence is mixed on the ability of PAs to manage such situations. Ekwo et al ${ }^{11}$ and Henry et al ${ }^{12}$ describe how, in the US, PAs appear to be managing such presentations independently and effectively, but, in the UK, literature suggests PAs are usually seeing patients who have been filtered in some way or another.?

The conceptual model allows the facilitators and barriers to be broadly simplified into three areas: a pragmatic response to rising demand with limited resources in the NHS; concern about the competencies in managing healthcare presentations in primary care; and barriers created by external legal and regulatory requirements.

PAs have been described as one of the potential solutions to help general practice meet demand at a time when the NHS is under greater pressure than ever before. With significant funding invested into expanding this role (among others), it is critical that there is a greater understanding of factors relating to their effective integration. This study has investigated the barriers and facilitators to the integration of PAs into the general practice workforce in a region completely unfamiliar with the role. Through a grounded theory approach, a conceptual model was created with foundations built on rooted stakeholder opinion, describing the many factors that may impede the introduction of PAs more widely into primary care settings. This model provides a framework to help regulators and educationalists who wish to support such integration to understand where to focus their attention, and may provide some guidance when considering other novel roles in primary care.

\section{Strengths and limitations}

The modified grounded theory methodology provides credibility to this study. ${ }^{8}$ This allowed themes generated directly from 
the community of primary care to shape the initial theoretical framework, and the focus of the literature search, with these themes then being formally tested through focus groups. That data saturation emerged after the third GP group; triangulation of these themes in the ANP and patient groups adds additional validity to the final model. The reflexive diary, kept throughout the study by one of the authors, professional transcription from audio recordings, and analysis through NVivo software confirm dependable data. The independent verification of the analysis provides further strength.

Limitations in the study also need to be recognised. Many of the GPs were already involved in training and supervision of general practice specialty trainees, and therefore, as a group, will be more familiar with clinical supervision in the workplace than the wider workforce. The general lack of knowledge regarding the role among participants will have naturally influenced some of the opinions voiced. However, this also adds credibility to the findings, as the study was designed to consider the question in a region unfamiliar with the role.

\section{Comparison with existing literature}

The findings are in keeping with the literature. Since its inception, the PA profession appears to have frequently occupied a space where a pragmatic response to service need is developing with limited resources. It is also clear that the profession has been more successful in filling this space where there are clear regional and national strategies regarding regulation of the role, particularly relating to prescribing. ${ }^{5.10}$ Where the role has been introduced to new areas, it has been shown that initial scepticism and antipathy from medical and other professionals can be replaced by an increasing recognition of the value in the role. The findings also support the literature in that patients are less concerned about new roles, supervision, and prescribing than GPs are, but that it helps if there is a clear explanation of such changes to the services on offer to them. . $^{6} 13,14$

This study also provides new evidence regarding the key concerns GPs and ANPs have of the suitability of newly qualified PAs to work in the context of primary care, mostly relating to competence in managing medical complexity, with an associated concern that the degree of supervision first required to support newly qualified PAs will be a significant burden. To balance this, interesting new evidence emerges on the added potential that PAs bring to primary care through their training in a generalist medical model, rather than those roles that adapt from a nursing or other background.

\section{Implications for practice}

This study suggests there are still considerable barriers in place to the integration of PAs into the primary care workforce. Further development of the PAs' profession was broadly recognised as a pragmatic response to rising demand in the NHS with limited resources. Patients and ANPs accepted this more than GPs, although opinion was mixed as to how best they might fit into primary care teams. It is likely patients will accept an expansion of the role, particularly if given more information.

There was concern about how prepared PAs would be to manage healthcare presentations in a primary care setting, particularly around medical complexity. This was most strongly voiced by GPs, but echoed by ANPs and recognised by patients. Professional and educational institutions involved in postgraduate education and training of PAs should reflect on curricular design and delivery in seeking to address this issue.

Additional barriers relate to regulatory factors, particularly with respect to prescribing rights and indemnity. A strategic approach to addressing this has been an important factor in supporting integration of the role internationally. It is unlikely that significant numbers of PAs will integrate into primary care teams until this is addressed.

Finally, there is a lack of understanding about the role and how it might support and complement other roles in general practice teams. Professional bodies, such as the UK Faculty of Physician Associates, should look to address this. Additionally. GPs may also look to their own professional bodies for more information and guidance on how such new clinical roles can safely and effectively support their teams.

Physician Associate Studies.

\section{Acknowledgements}

The authors wish to thank Dr Caroline Mitchell and Professor Chris Burton for their helpful review and comments.

\section{Discuss this article}

Contribute and read comments about this article: bjgp.org/letters 


\section{REFERENCES}

1. Appleby J, Robertson R. Public satisfaction with the NHS in 2015: results and trends from the British Social Attitudes survey. London: King's Fund, 2016. https://www.kingsfund.org.uk/publications/public-satisfaction-nhs-2015 laccessed 13 Sep 2017).

2. Primary Care Workforce Commission, Health Education England. The future of primary care. Creating teams for tomorrow. HEE, 2015.

3. Hawkes N. Array of out-of-hours and emergency services is confusing to public, says NHS chief. BMJ 2014; 349: g7186.

4. NHS England. General practice foward view. 2016. https://www.england.nhs.uk/ wp-content/uploads/2016/04/gpfv.pdf (accessed 13 Sep 2017).

5. Cawley JF, Hooker RS. Physician assistants in American medicine: the half century mark. Am J Man Care 2013; 19(10): e333-e341.

6. Woodin J, Mc Leod H, McManus R, Jelphs K. Evaluation of US-trained physician assistants working in the NHS in England. Health Services Management Centre, 2005.

7. Drennan VM, Halter M, Brearley S, et al. Investigating the contribution of physician assistants to primary care in England: a mixed-methods study. Health Serv Deliv Res 2014; http://www.journalslibrary.nihr.ac.uk/hsdr/volume-2/issue16 laccessed 13 Sep 2017).

8. Charmaz K. Grounded theory. In: Smith J, Harre R, van Langenhove L, eds. Rethinking methods of psychology. London: Sage, 1995: 27-49.

9. Arksey H, O'Malley L. Scoping studies: towards a methodological framework. Int J Soc Res Methodol 2005; 8(1): 19-32.

10. Wright DD, Kane RL, Snell GF, Woolley FR. Costs and outcomes for different primary care providers. J Am Med Assoc 1977; 238(1): 46-50.

11. Ekwo $E$, Daniels M, Oliver D, Fethke $C$. The physician assistant in rural primary care practices: physician assistant activities and physician supervision at satellite and non-satellite practice sites. Med Care 1979; 17(8): 787-795.

12. Henry LR, Hooker RS, Yates K. The role of physician assistants in rural health care: a systematic review of the literature. J Rural Health 2011; 27(2): 220-229.

13. Henry LR, Hooker RS. Caring for the disadvantaged: the role of physician assistants. JAAPA 2014; 27(1): 36-42.

14. Halter M, Drennan V, Chattopadhyay K, et al. The contribution of physician assistants in primary care: a systematic review. BMC Health Serv Res 2013; 13: 223. 